\title{
PRESSURE ACTUATED LEAF SEALS FOR IMPROVED TURBINE SHAFT SEALING
}

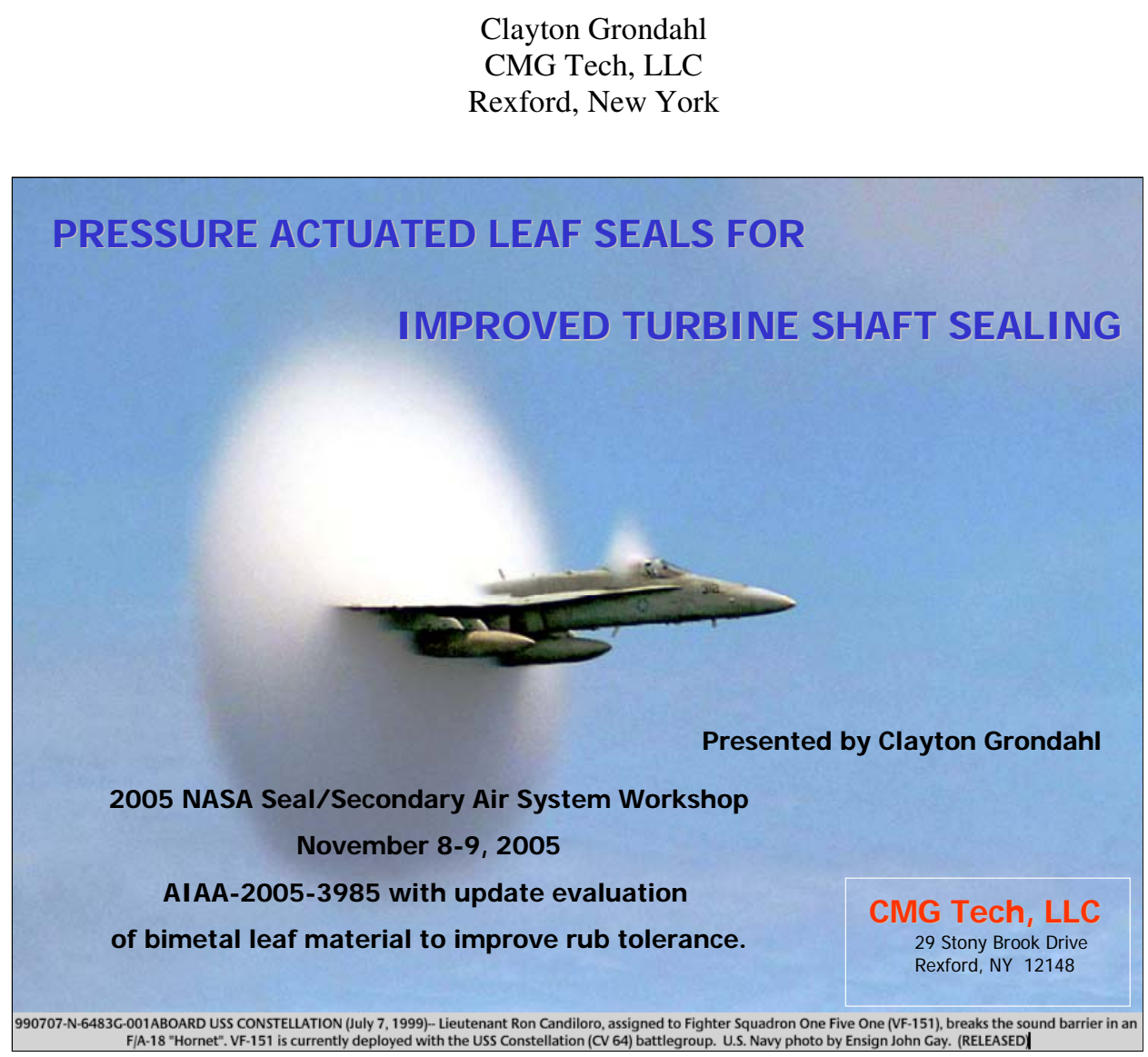

This presentation introduces a shaft seal in which leaf seal elements are constructed from slotted shim material formed and layered into a frusto-conical assembly. Limited elastic deflection of seal leaves with increasing system pressure close large startup clearance to a small, non-contacting, steady state running clearance. At shutdown seal elements resiliently retract as differential seal pressure diminishes. Large seal clearance during startup and shutdown provides a mechanism for rub avoidance. Minimum operating clearance improves performance and non-contacting operation promises long seal life. Design features of this seal, sample calculations at differential pressures up to 2400 psid and benefit comparison with brush and labyrinth seals is documented in paper, AIAA-2005-3985, presented at the Advanced Seal Technology session of the Joint Propulsion Conference in Tucson this past July. In this presentation use of bimetallic leaf material will be discussed. Frictional heating of bimetallic leaf seals during a seal rub can relieve the rub condition to some extent with a change in seal shape. Improved leaf seal rub tolerance is expected with bimetallic material. 


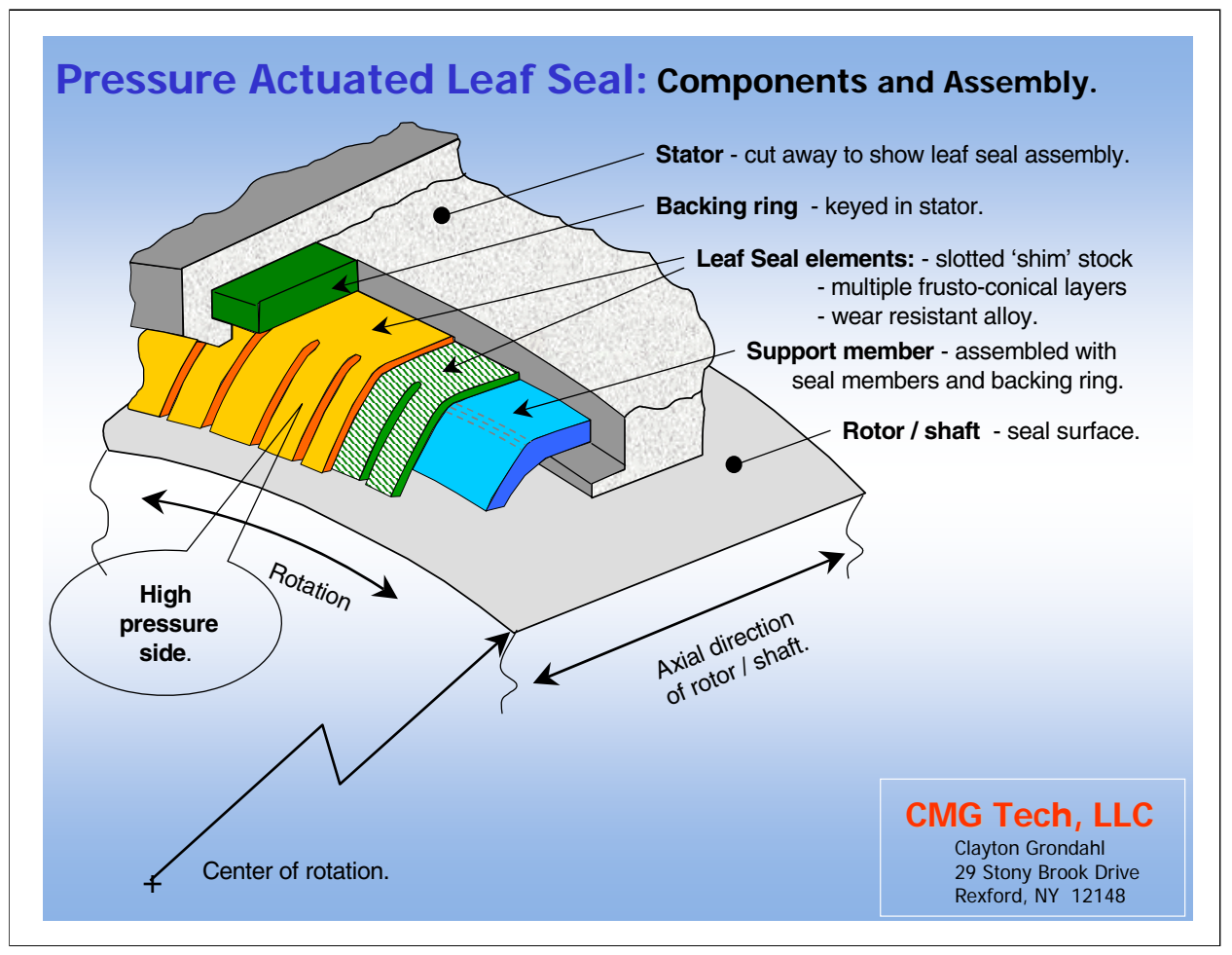

Pressure actuated leaf seal features are patented per US 6644667 or Patent Pending per publication US 2004/0150165.

Leaf Seal assembly contains as few as 4 components. 


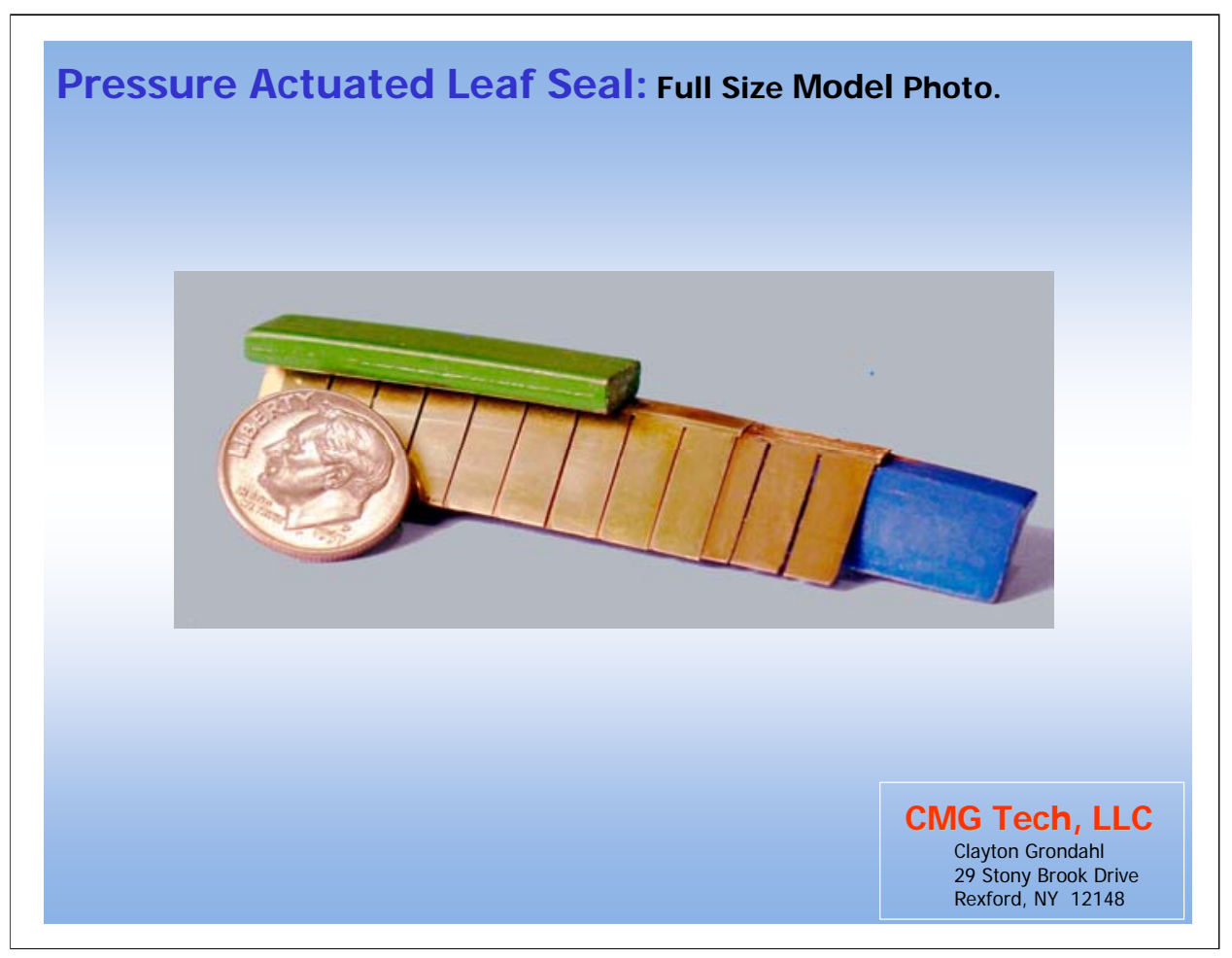

Leaf seal radial height and axial length is small, of the order of 0.5 inches as shown. 


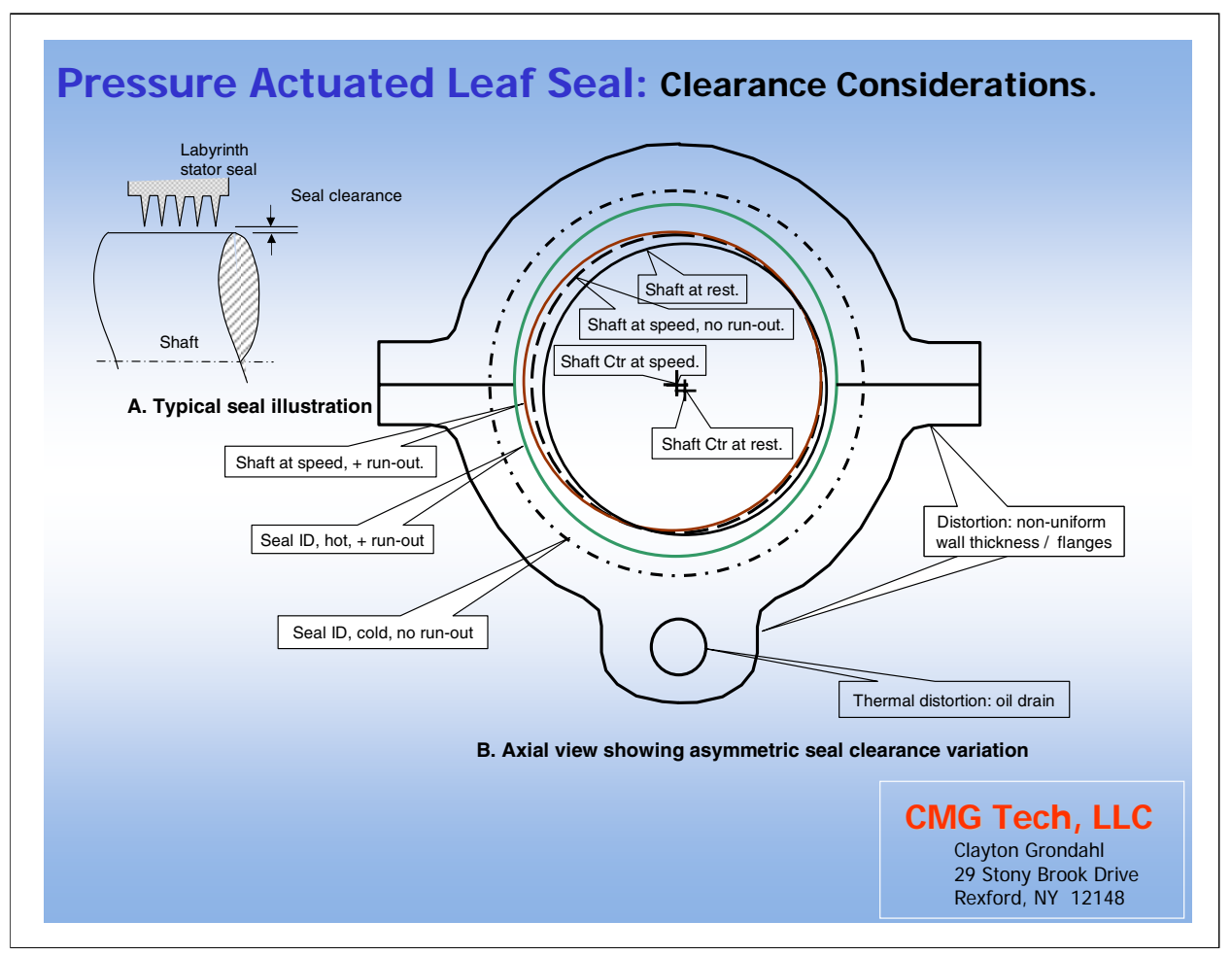

Turbo machinery seal clearances are neither static or uniform. Hence the need for a robust resilient seal. 


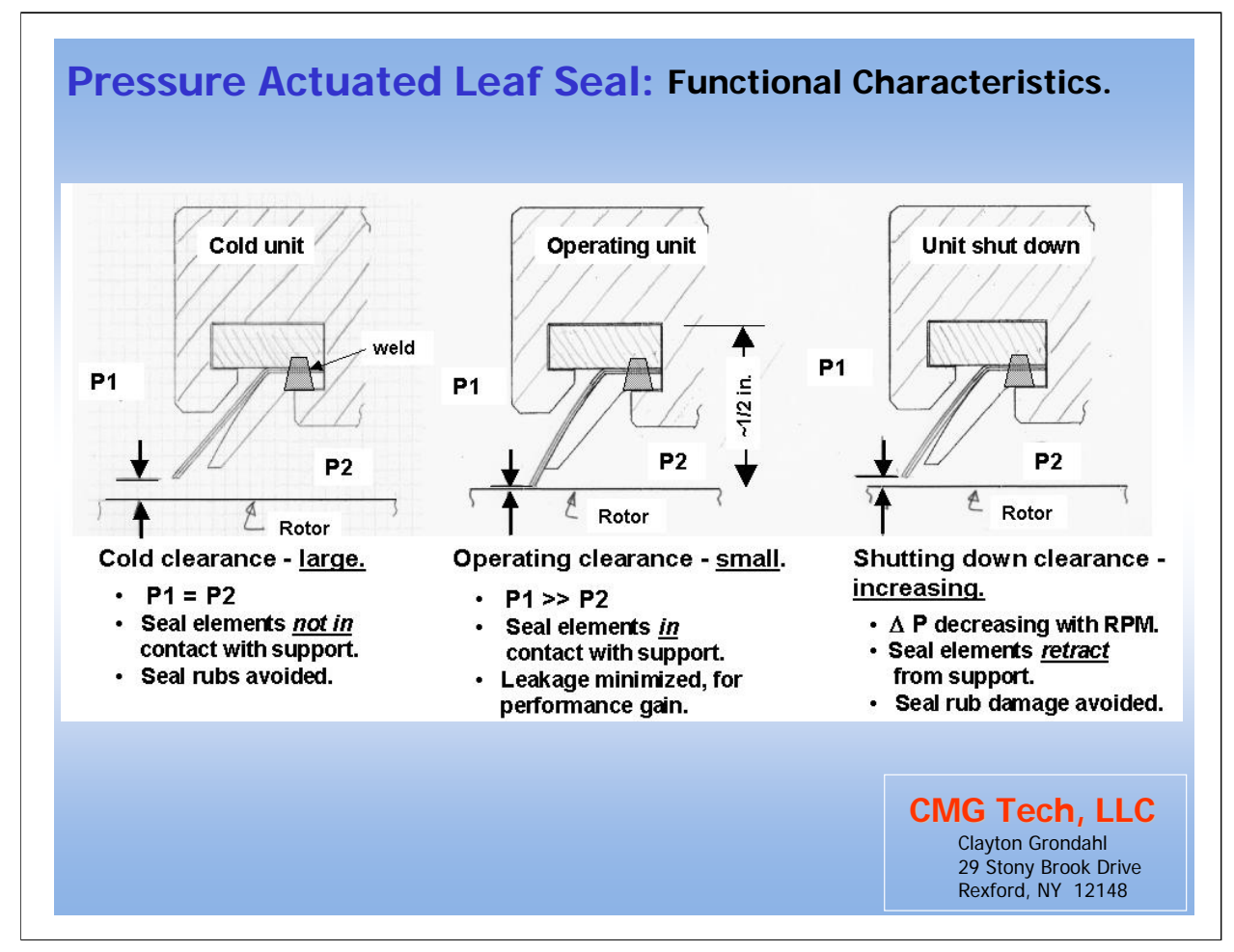

A radius on the high pressure side of the support member facilitates flexure of the frusto-conical leaf seal members toward the shaft as pressure is applied.

Large seal clearance at startup and shutdown minimizes seal rub hazard during these most vulnerable periods.

Small seal clearance at normal operating conditions provides performance benefits. 


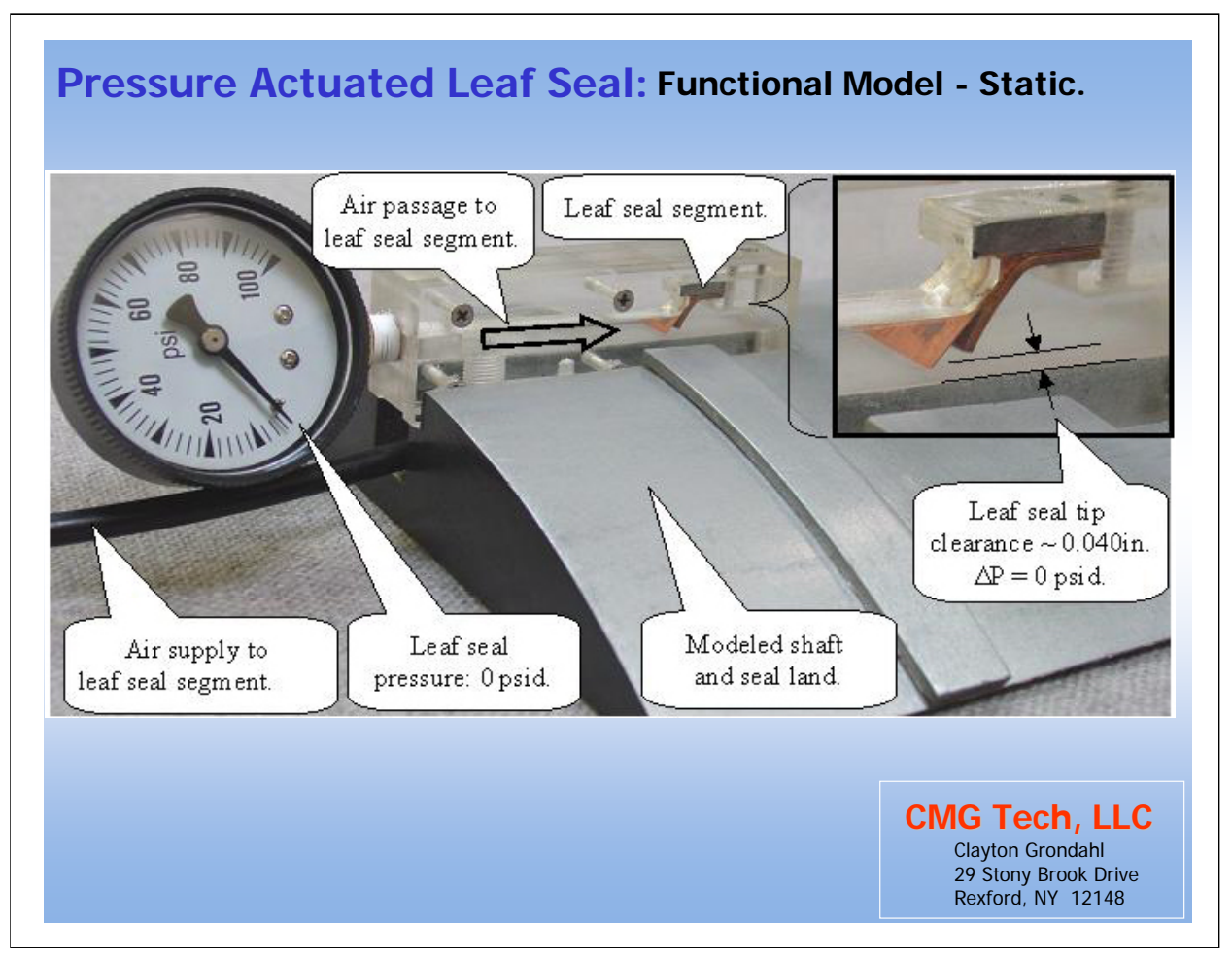

Static model shows large clearance under leaf tip without differential seal pressure. 


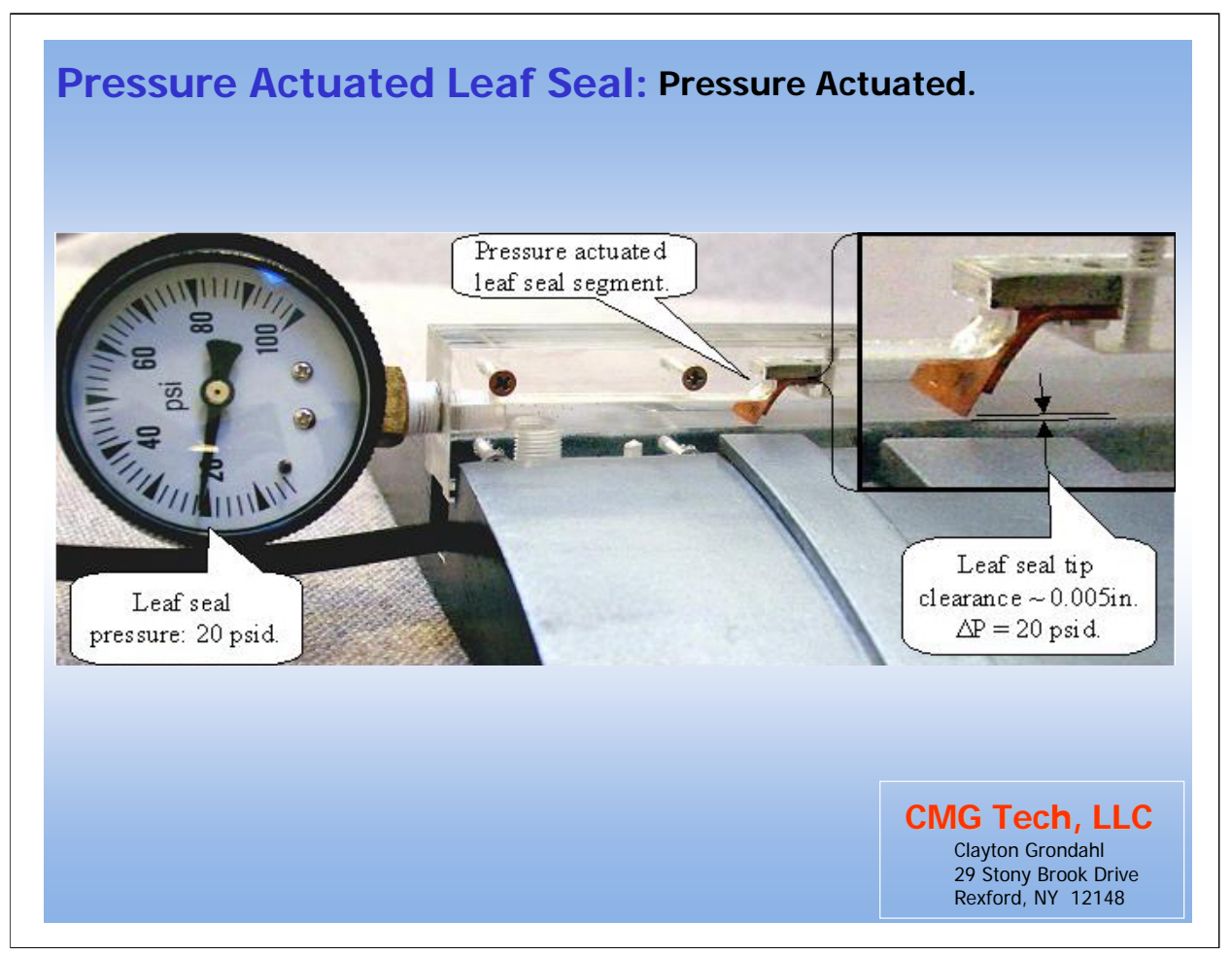

Pressurized model shows small clearance under leaf tip with differential seal pressure applied. 


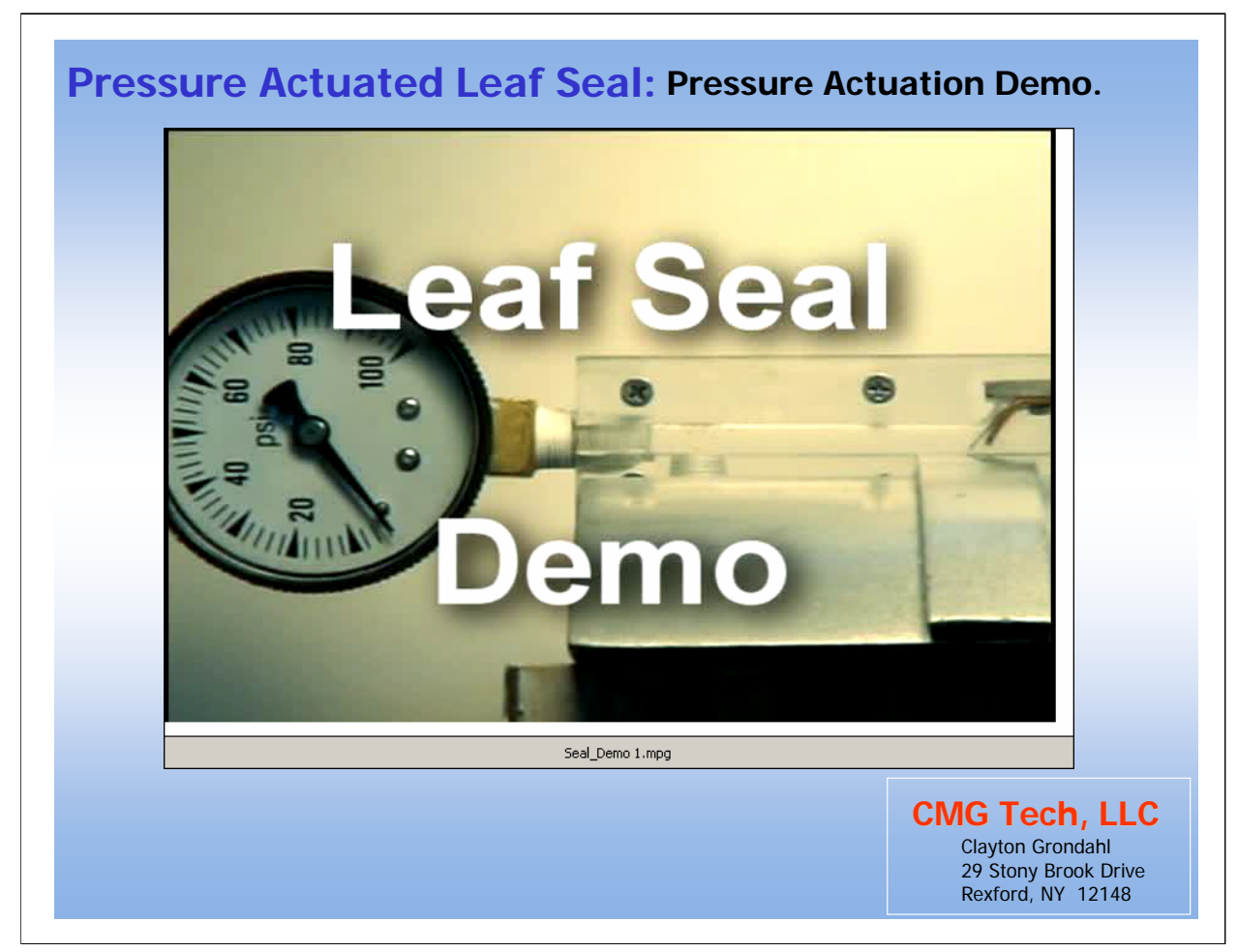

Video shows action of the previous 2 slides. 


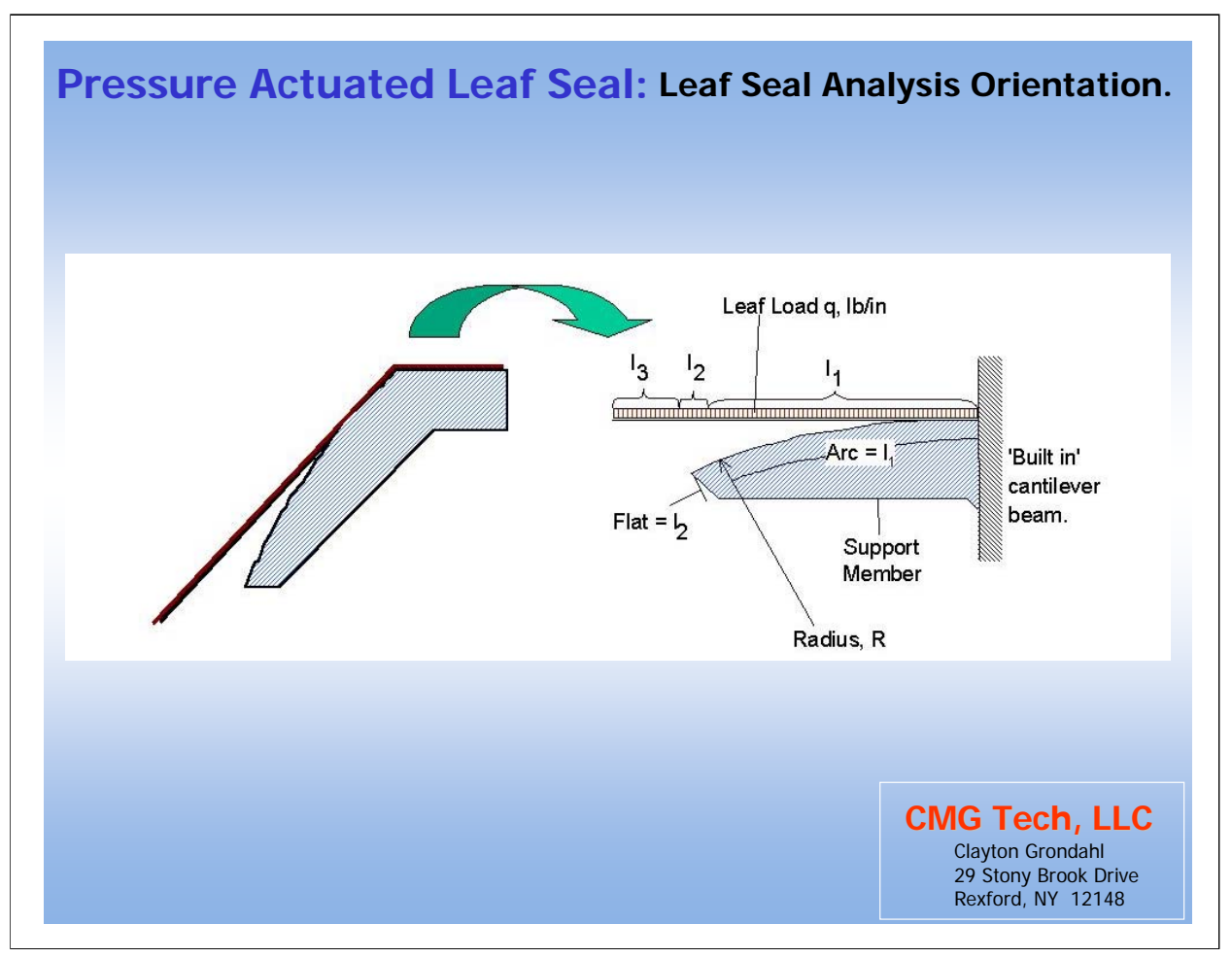

Preliminary stress analysis and leaf bending has considered leaves as beams in bending. 


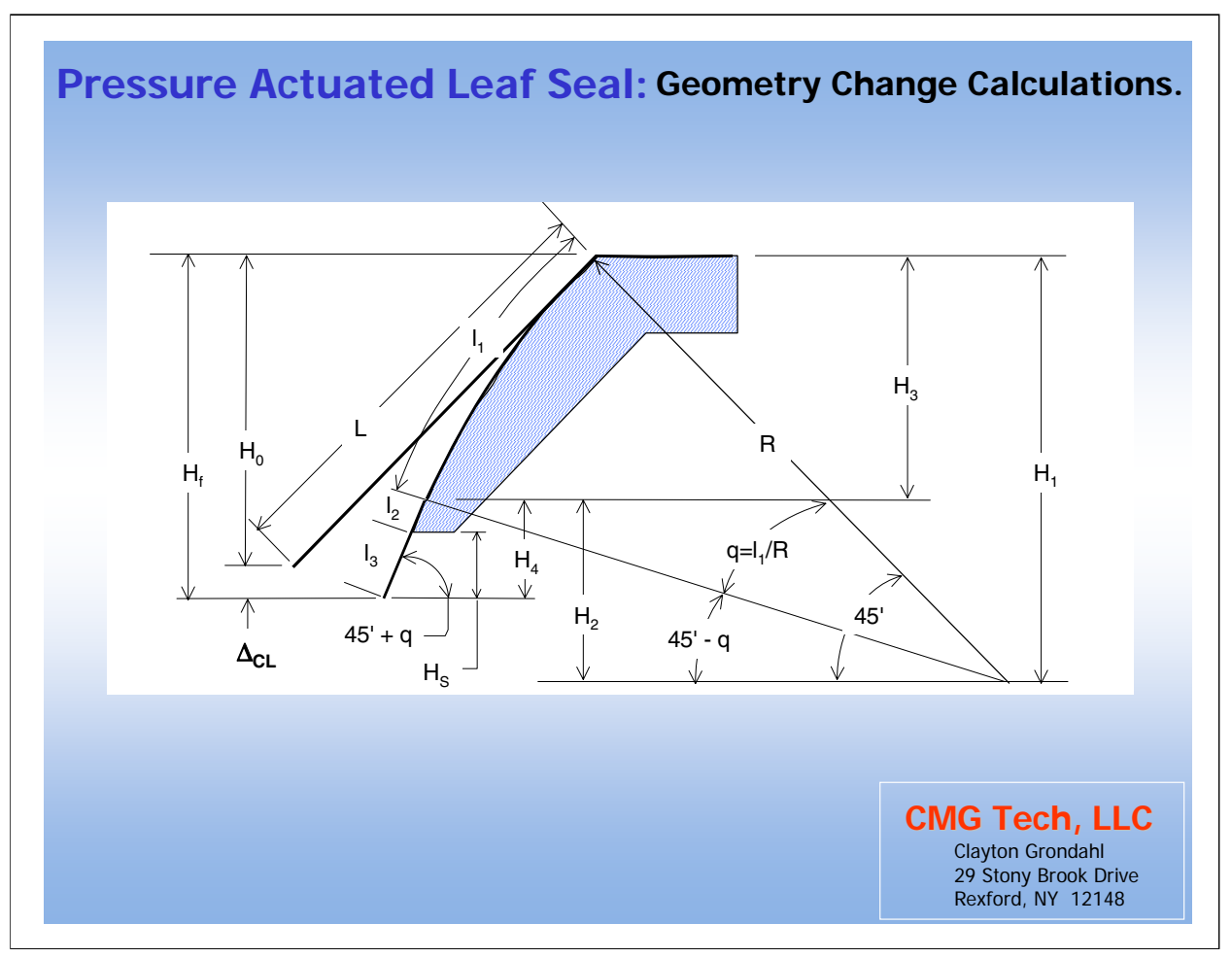

Change in clearance is calculated from geometry shown. 


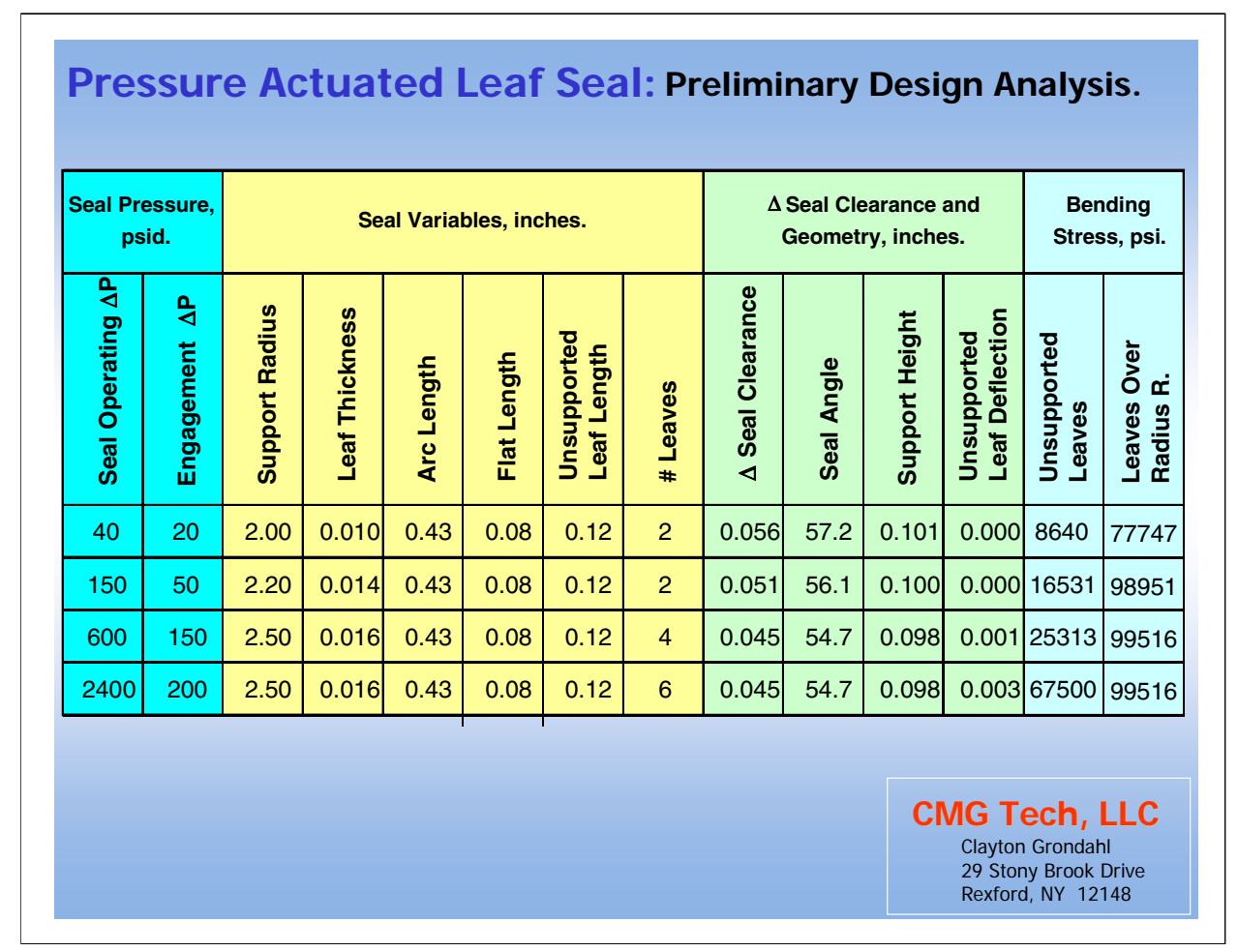

A large range of differential seal pressure capability is tabulated here using various leaf thickness, support radius, and number of leaves. Acceptable leaf stress is shown in applications up to 2400 psi differential seal pressure.

In all cases, substantial seal closure of $\sim 0.05$ in is shown to be possible. 


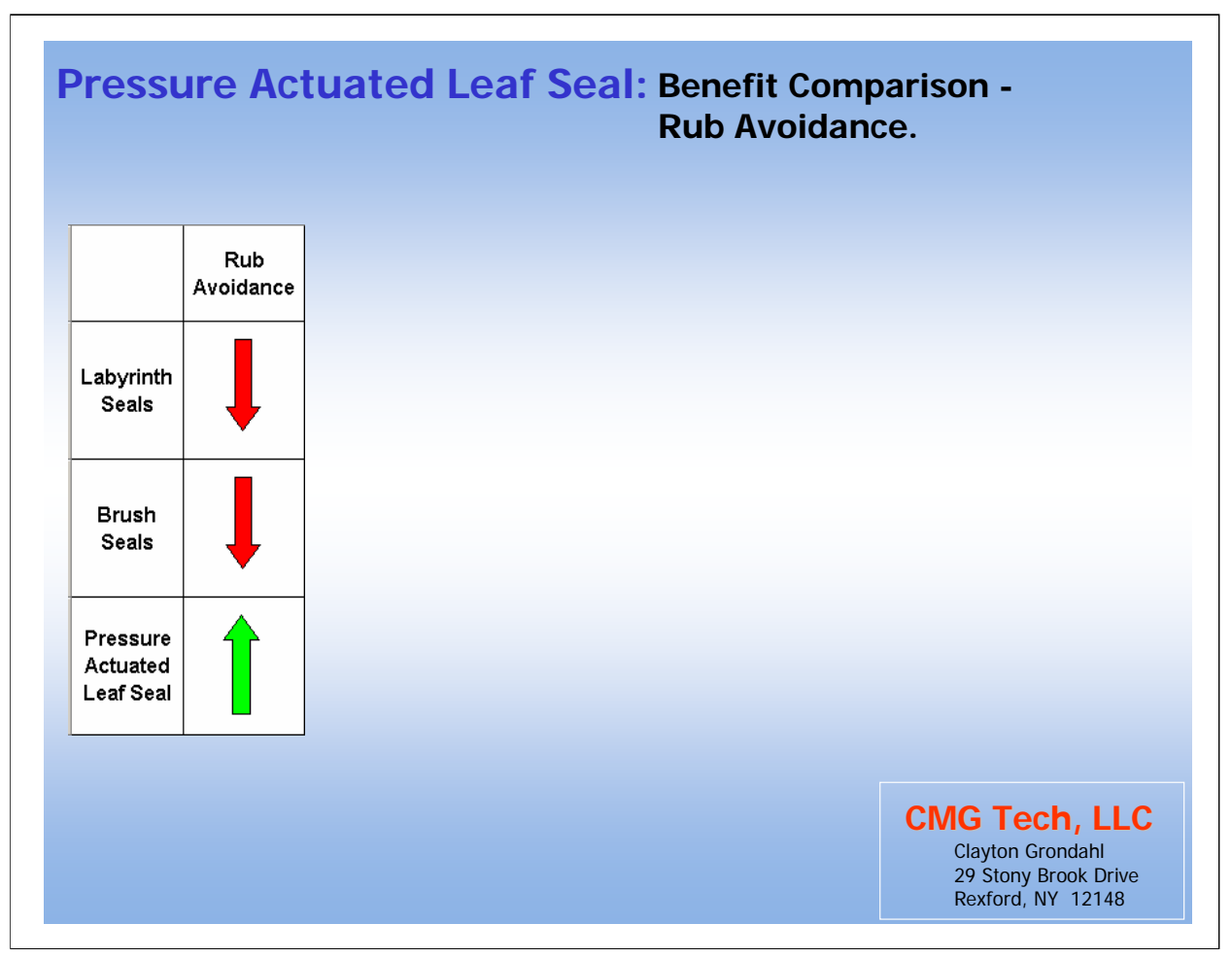




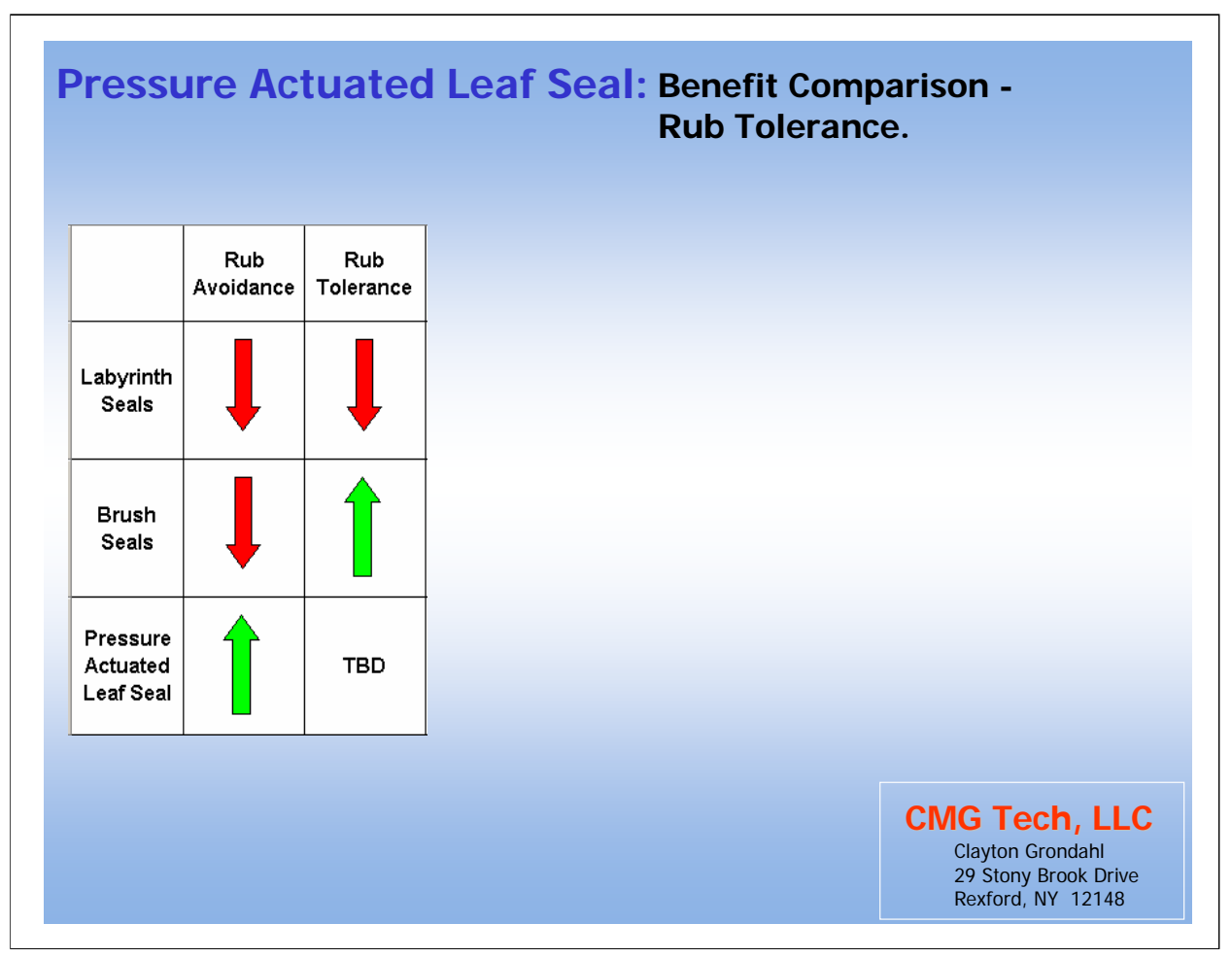




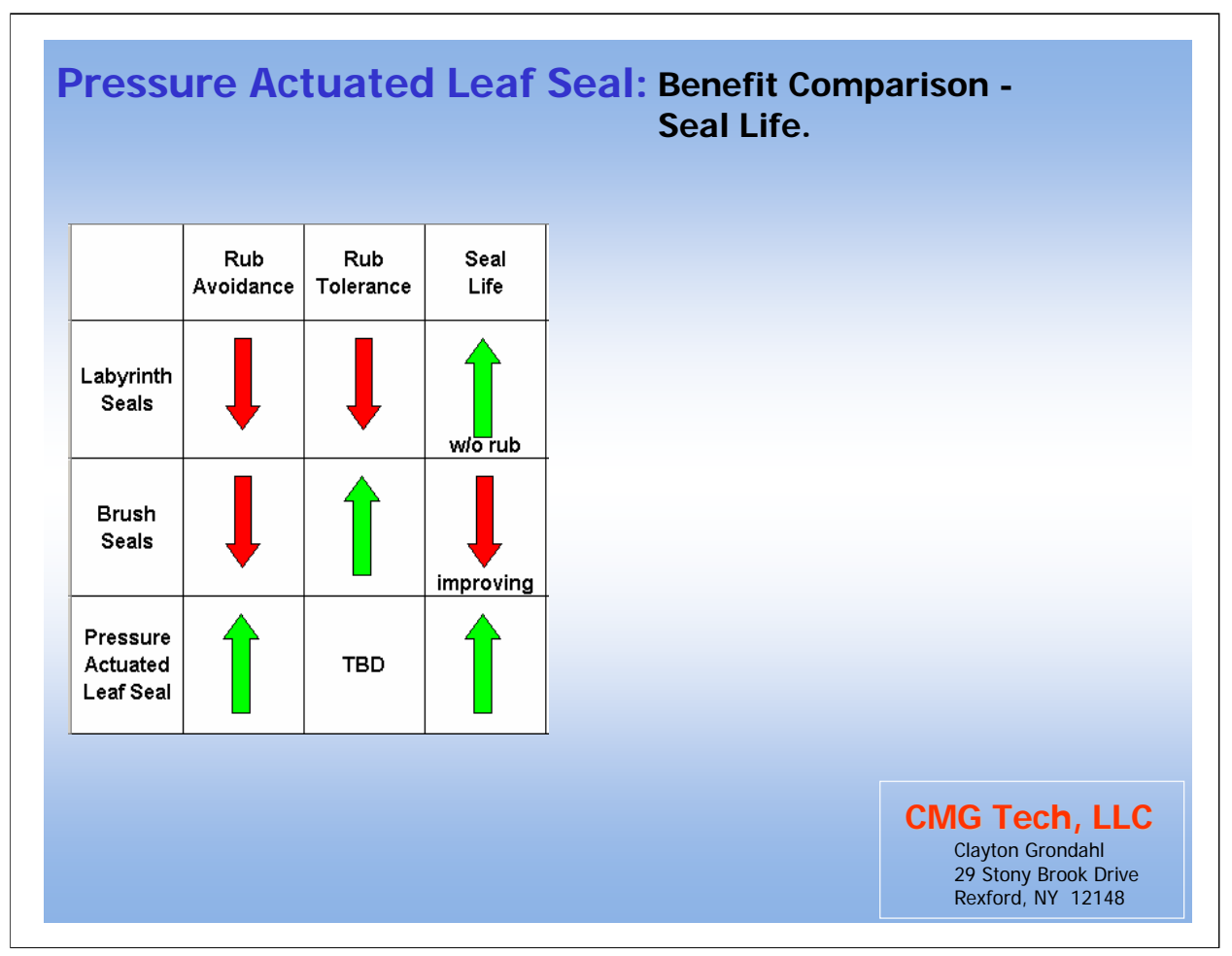




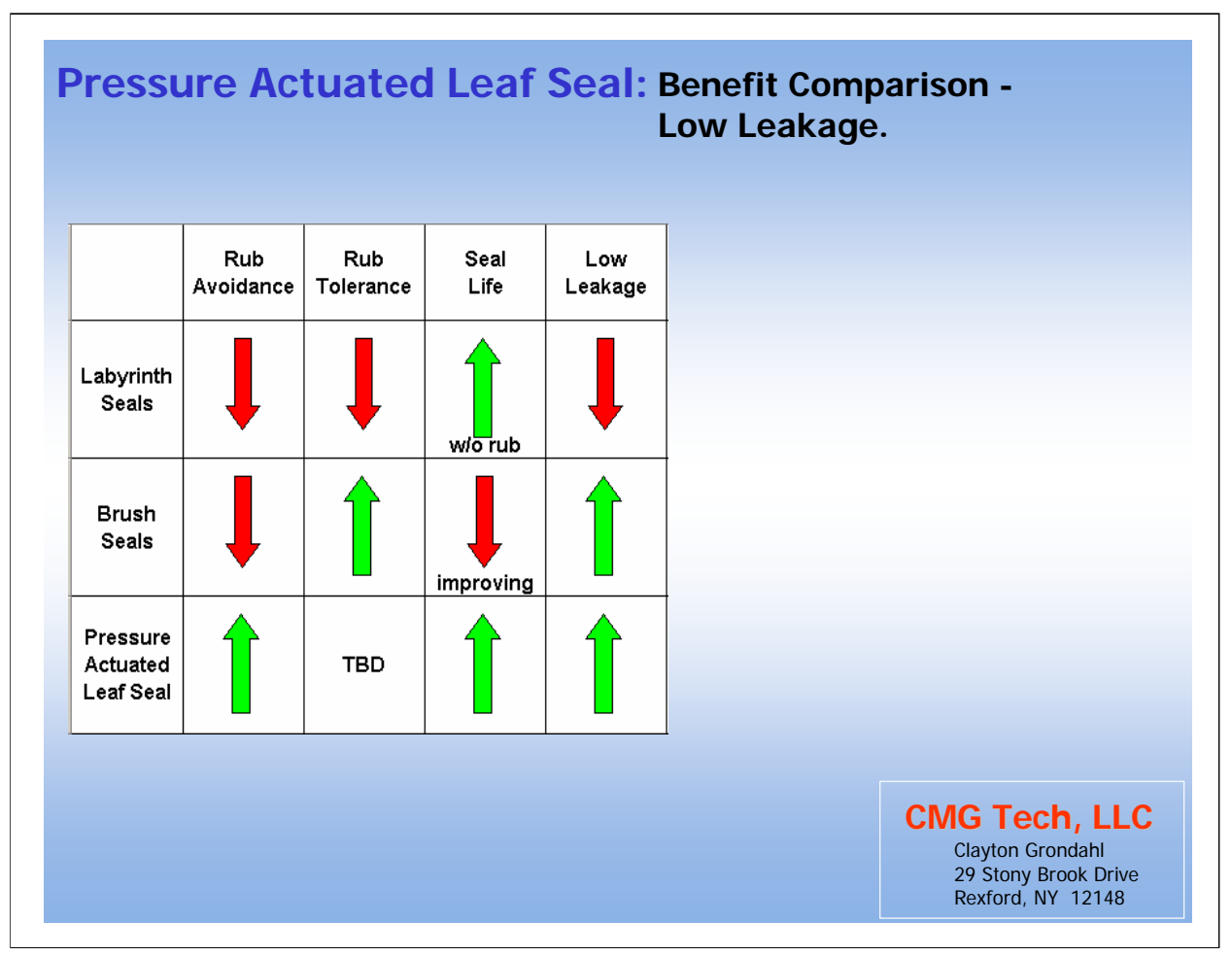




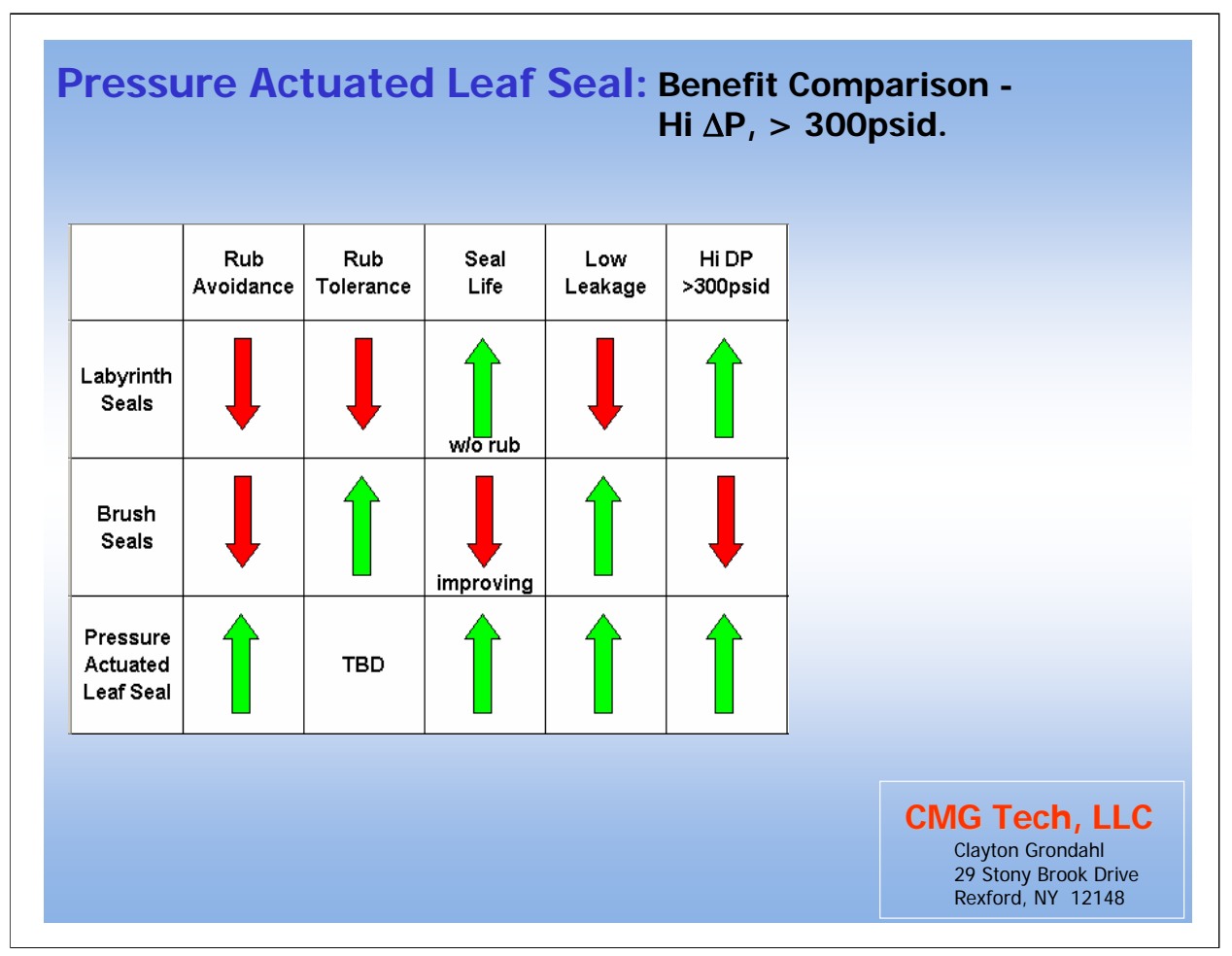




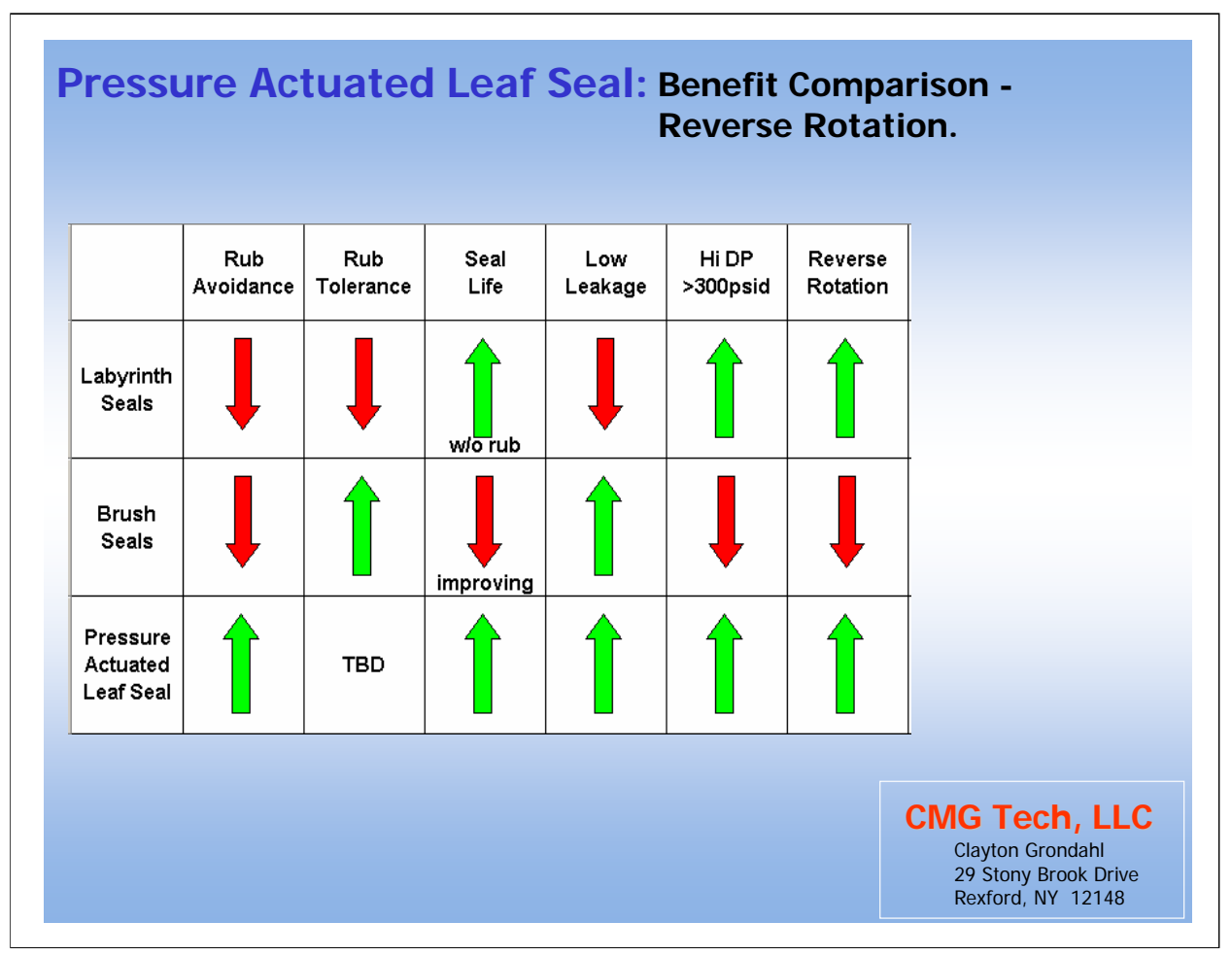




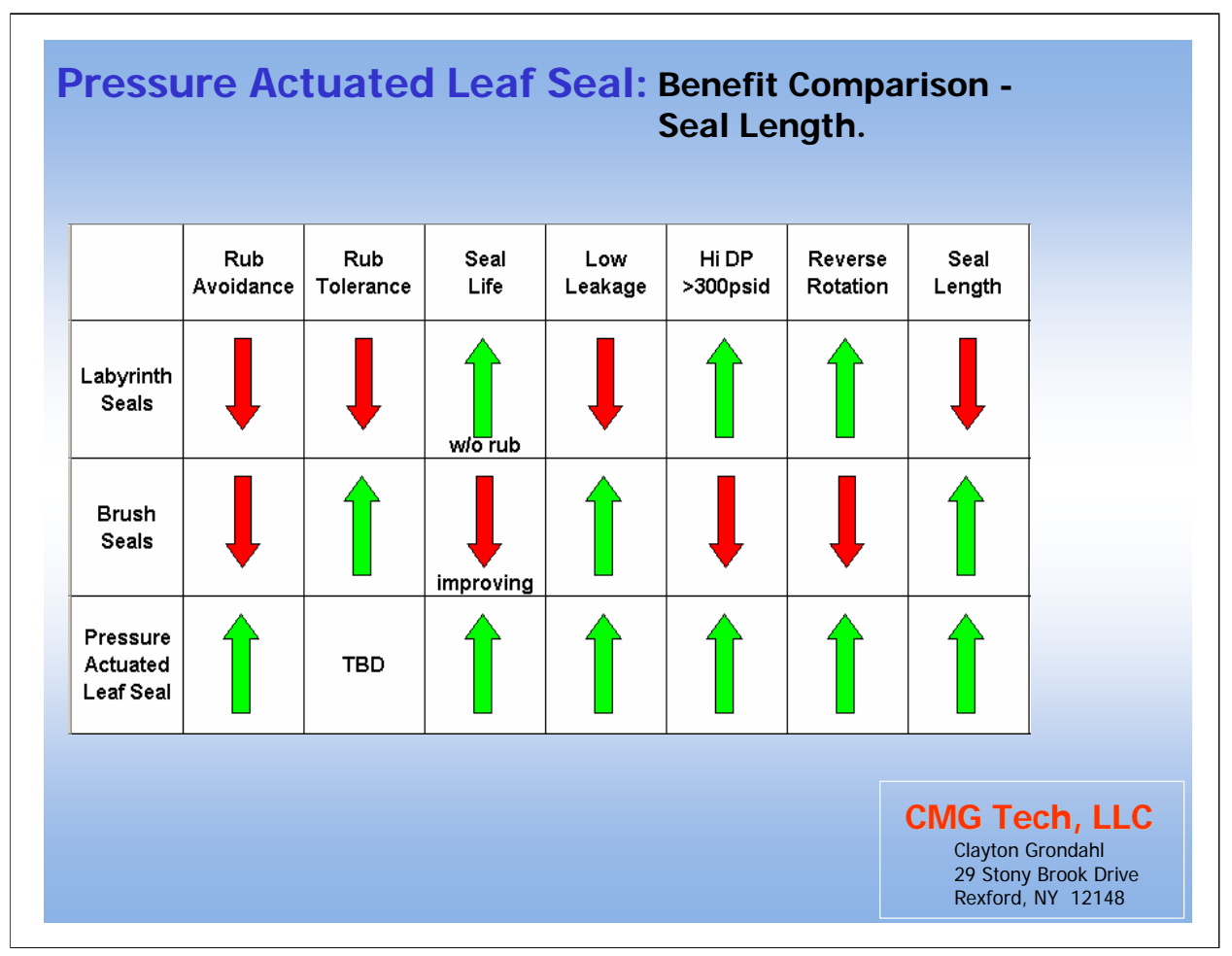




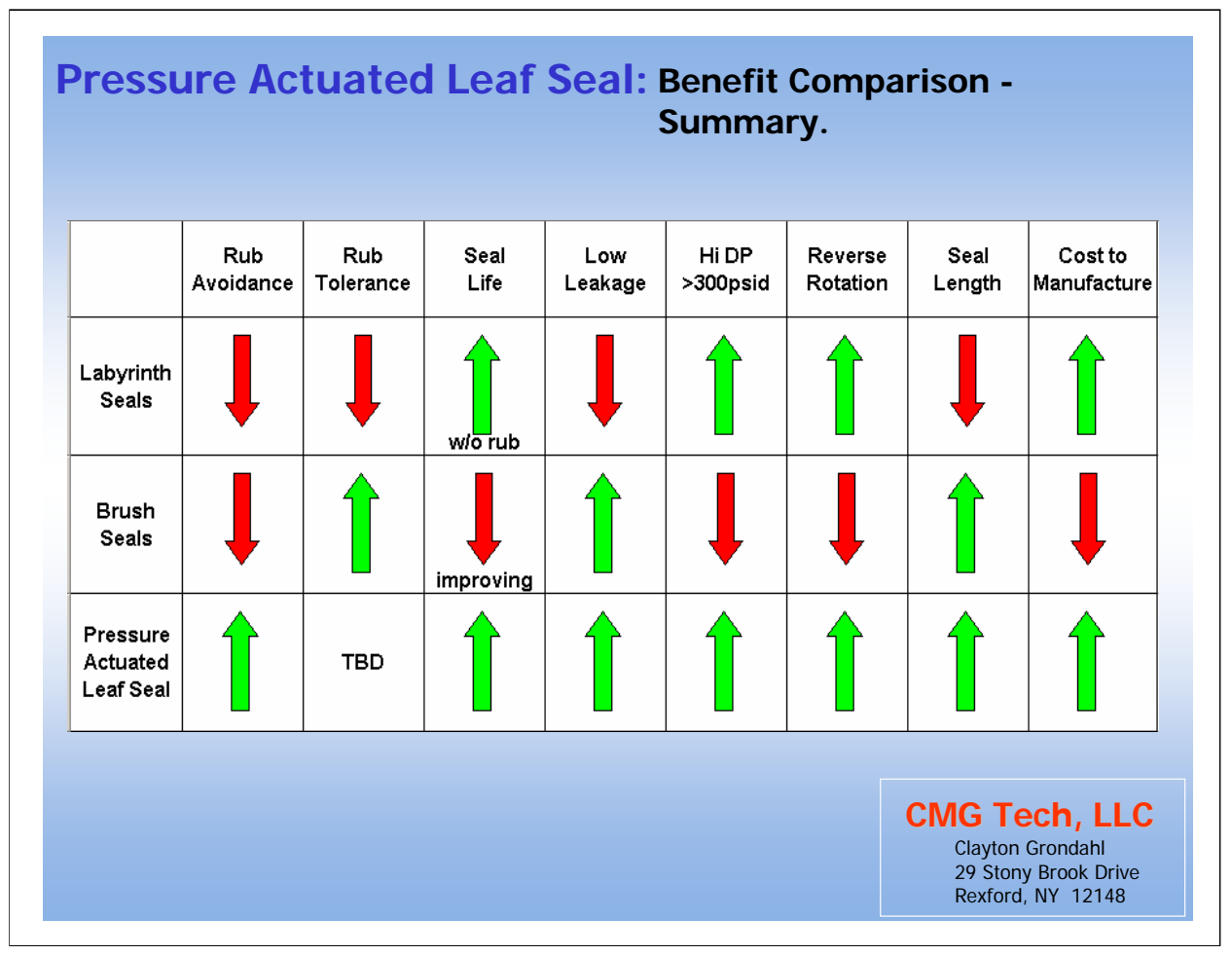

Pressure Actuated Leaf Seal benefits, compared to both labyrinth seals and brush seals, shows a strong basis for development. 


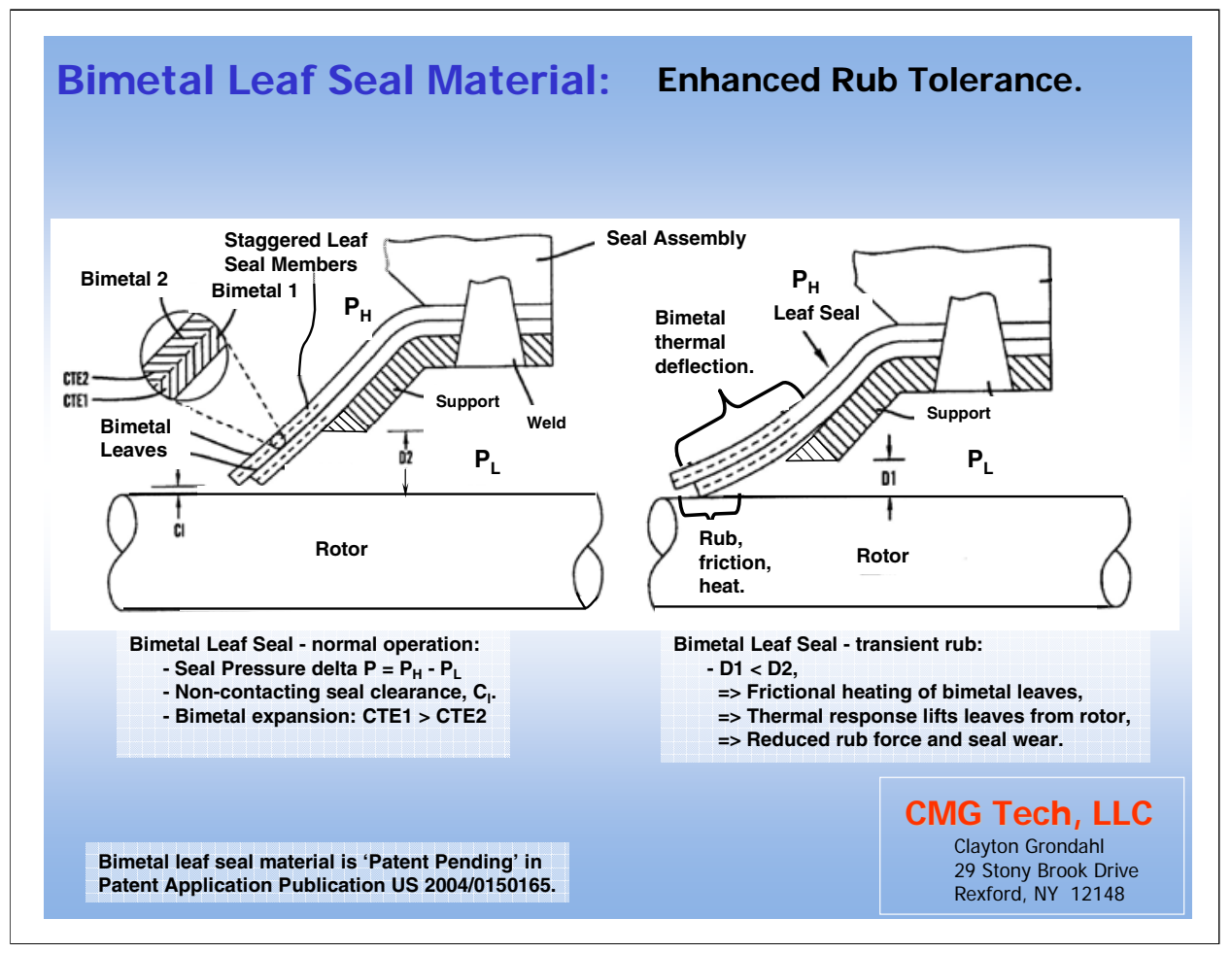

Leaf seal rub tolerance may be enhanced by use of bimetallic leaf material as illustrated. 


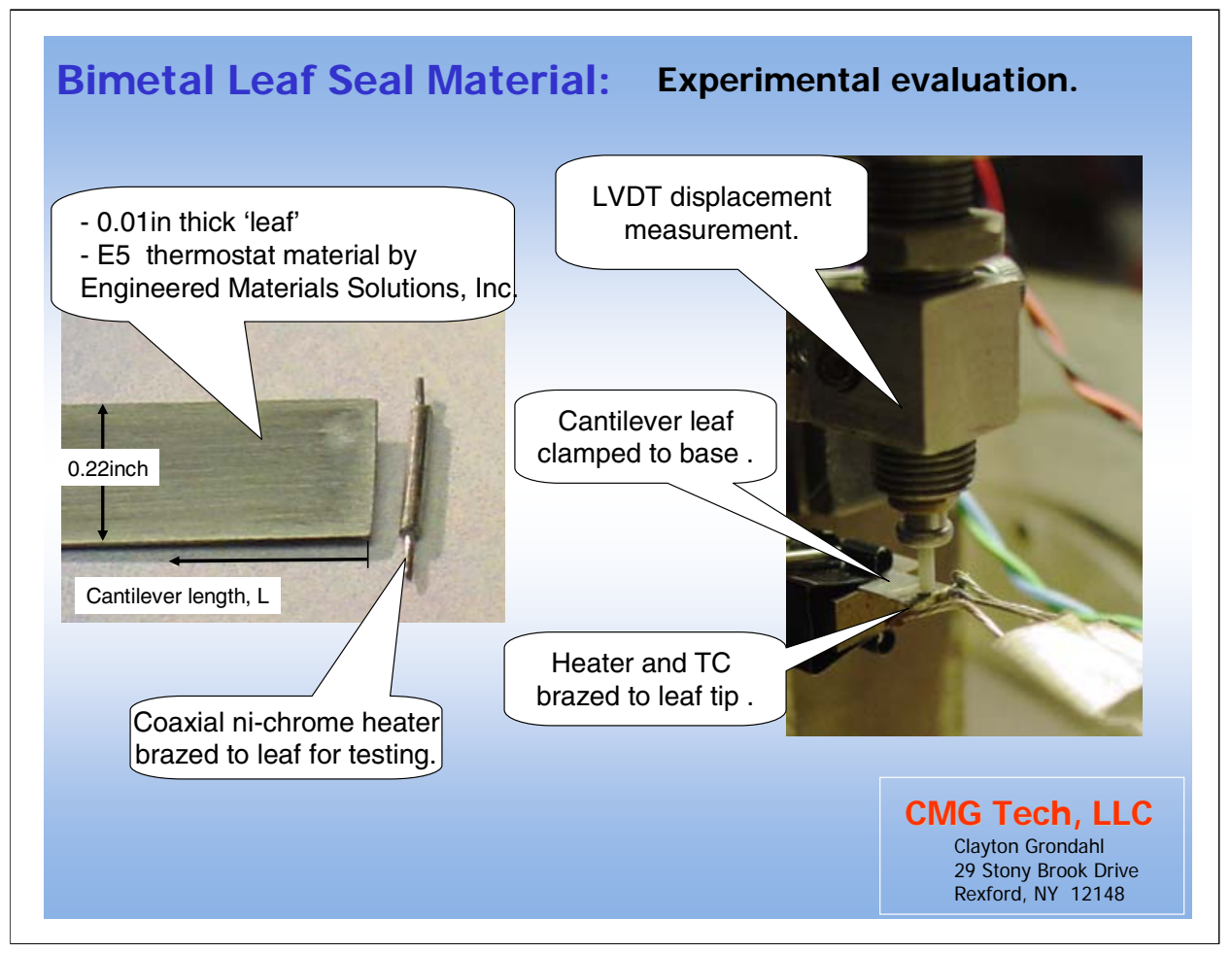

A selected bimetal leaf material was tested to show concept feasibility. 


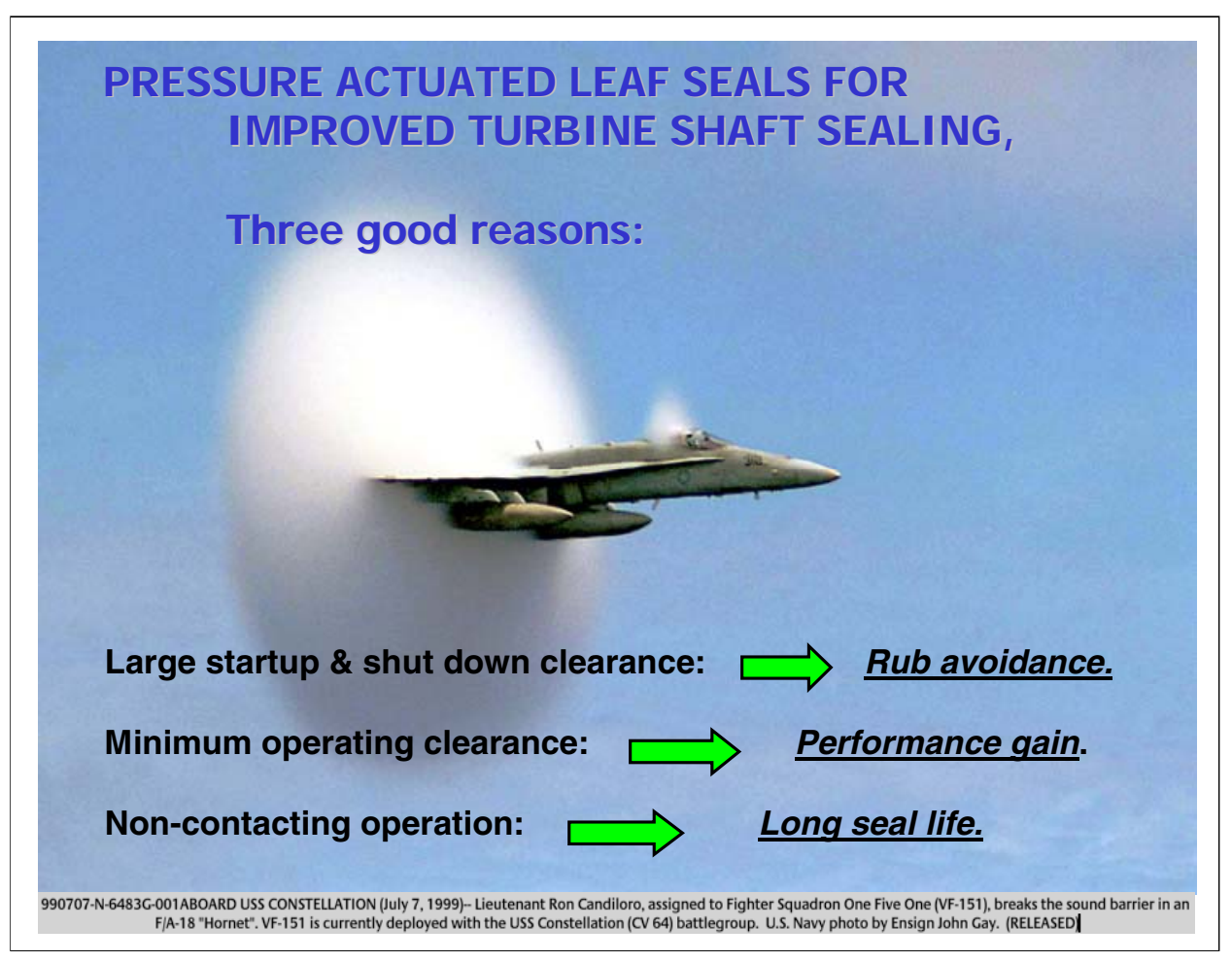

There appears to be an adequate rationale for the development of the Pressure Actuated Leaf Seal for a wide range of applications. 


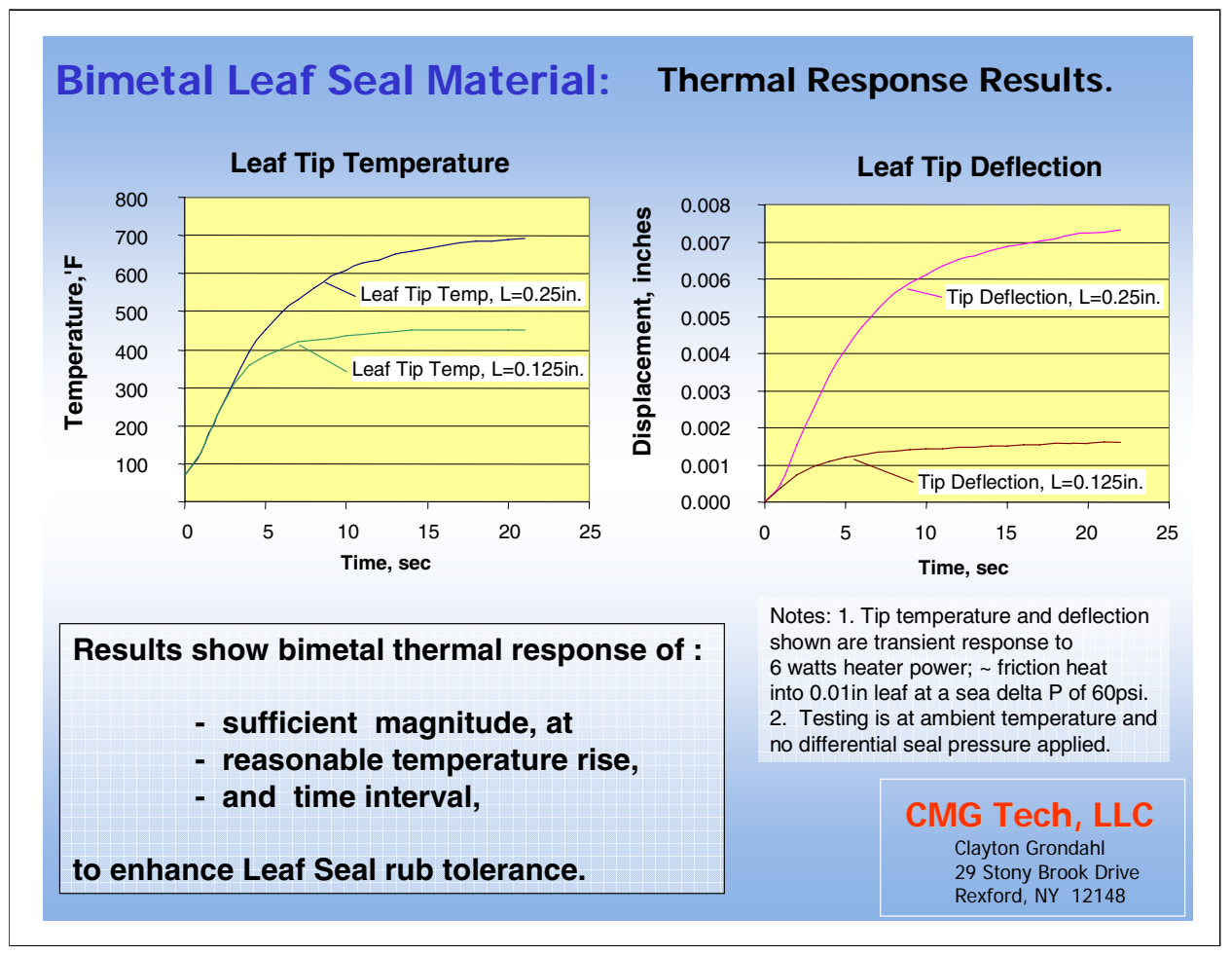

Test results show that a bimetal leaf of proximate seal geometry can respond rapidly to a change in tip temperature and deflect several mils. In a seal application movement away from a moving component could relieve friction heating during a transient rub. 